\title{
Growth of One-dimensional Gallium Nitride Nano- and Microstructures in an Alumina Matrix Containing Gallium Oxide
}

\author{
Woo-Sik Jung \\ School of Chemical Engineering and Technologw, College of Engineering, Yeungnam University, Gyeongsan 712-749, Korea \\ E-mail:wsiung@yiac.kr \\ Received March 17, 2006
}

Key Words : Gallium nitride, GaN, Nanowire, Microstructure, VS mechanism

Nanostructures of gallium nitride ( $\mathrm{GaN}$ ) with a direct bandgap of $3.4 \mathrm{eV}$ are of interest because of their great prospects in fundamental physical science, novel nanotechnology applications, and significant potential in optoelectronics.' One-dimensional nanostructures such as nanowires and nanorods have been grown by various methods. Most of them are based on the chemical vapor deposition (CVD) of $\mathrm{GaN}$ on the substrate. The substrate is coated with transition metals such as $\mathrm{Ni},{ }^{3.3} \mathrm{Fe},{ }^{1,5} \mathrm{Co},{ }^{5} \mathrm{In}^{6}$ and $\mathrm{Au},{ }^{7}$ which inevitably results in undesired contamination within $\mathrm{GaN}$ nanostructures. One of the useful synthetic methods to avoid the contamination is to employ the so-called confined reactor such as the carbon nanotube ${ }^{\gamma}$ or the anodic alumina membrane.? GaN nanowires were obtained by placing the confined reactor on a mixture of $\mathrm{Ga}$ and $\mathrm{Ga}_{2} \mathrm{O}_{3}$ and calcining it under a flow of ammonia at temperatures $\geq 900^{\circ} \mathrm{C} .{ }^{8.9}$ Their growth mechanism in the reactor remains unknown.

In this report we prepare one-dimensional GaN nano- and microstructures by using a confined reactor made of alumina containing a $\mathrm{Ga}$ source and propose their growth mechanism.

\section{Experimental Section}

A homogeneous mixture of aluminum oxyhydroxide and gallium oxyhydroxide (mole ratio $=1: 0.05$ ) was prepared by mixing $\mathrm{Al}(\mathrm{III})$ and $\mathrm{Ga}$ (III) hydrolysis gels, filtering, and then drying the mixture in an oven. Each hydrolysis ge] was obtained by refluxing a mixture of metal nitrate salt and urea (mole ratio $=1: 4$ ) in aqueous solution. The mixture was calcined at $500{ }^{\circ} \mathrm{C}$ for $2 \mathrm{~h}$ under a flow of nitrogen and ground in mortar with a pestle. The resulting precursor powder was pressurized into a pellet. The precursor powder and its pellet were placed in an alumina crucible and then heated at a rate of $5{ }^{\circ} \mathrm{C} \mathrm{min}$ to the reaction temperature $\left(700-950{ }^{\circ} \mathrm{C}\right)$ under a flow of ammonia (Showadenko Co., $99.999 \%$ ). The flow rate was, if not stated otherwise, $50 \mathrm{~mL} \mathrm{~min}{ }^{-1}$. The duration time was $5 \mathrm{~h}$. The products were taken from the furnace after they were cooled to the room temperature under a flow of ammonia. A homogeneous mixture of $\mathrm{NaF}$ and gallium oxyhydroxide (weight ratio $=1: 0.1$ ) was pressurized into a pellet and nitrided in order to investigate the effect of the confined reactor material on growth of $\mathrm{GaN}$ nanostructure.

The products were characterized by XRD (Rigaku
DMX-2500 diffractometer with $\mathrm{Cu}-\mathrm{K} \alpha$ radiation operating at $40 \mathrm{kV}$ and $100 \mathrm{~mA}$ ). The morphology of $\mathrm{GaN}$ products was investigated by scanning electron microscopy (SEM, Hitachi S-4100).

\section{Results and Discussion}

The hydrolysis of Ga(III) salt by decomposition of urea in aqueous solution gives a gel precipitation of gallium oxyhydroxide $(\mathrm{GaOOH}) .^{10}$ The precipitate tums into $\alpha$ $\mathrm{Ga}_{2} \mathrm{O}_{3}$ and then $\mathrm{GaN}$ by the reaction of $\mathrm{NH}_{3}$ above $800^{\circ} \mathrm{C}$ without the phase transformation from $\alpha-$ to $\beta-\mathrm{Ga}_{2} \mathrm{O}_{3} .{ }^{10} \mathrm{On}$ the other hand, the gel obtained by hydrolysis of $\mathrm{Al}$ (III) salt transforns into $\mathrm{Al}_{2} \mathrm{O}_{3}$ on its calcination at $500{ }^{\circ} \mathrm{C}$. As a consequence, the precursor powder in which $\mathrm{Ga}_{2} \mathrm{O}_{3}$ is dispersed in an $\mathrm{Al}_{2} \mathrm{O}_{3}$ matrix was obtained by calcining the homogeneous mixture of $\mathrm{Al}(\mathrm{III})$ and $\mathrm{Ga}$ (III) gels at $500^{\circ} \mathrm{C}$. The precursor powder and its pressurized pellet were nitrided at different reaction temperatures under a flow of ammonia. Figure I shows the X-ray diffraction pattem of the product obtained by the nitridation of the precursor powder at $850^{\circ} \mathrm{C}$, indicating that the product consists of both $\mathrm{GaN}$ and $\gamma-\mathrm{Al}_{2} \mathrm{O}_{3}$. It is evident, therefore, that $\mathrm{NH}_{3}$ gas diffused into the alumina matrix enough to react with $\mathrm{Ga}_{2} \mathrm{O}_{3}$ in a small space. Product powders obtained between 800 and 950

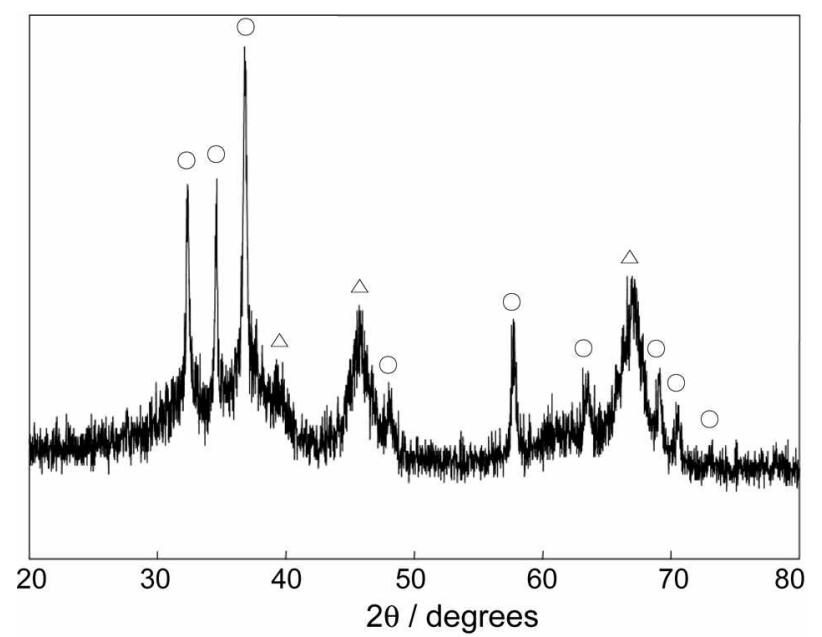

Figure 1. XRD pattern of powder obtained by calcining of a mixture of $\mathrm{GaOOH}$ and $\mathrm{AlOOH}$ at $850^{\circ} \mathrm{C}$ for $5 \mathrm{~h}$ under a flow of aunonia. $\mathrm{O}, \mathrm{GaN} ; \triangle, \gamma \mathrm{Nl}_{2} \mathrm{O}_{3}$. 

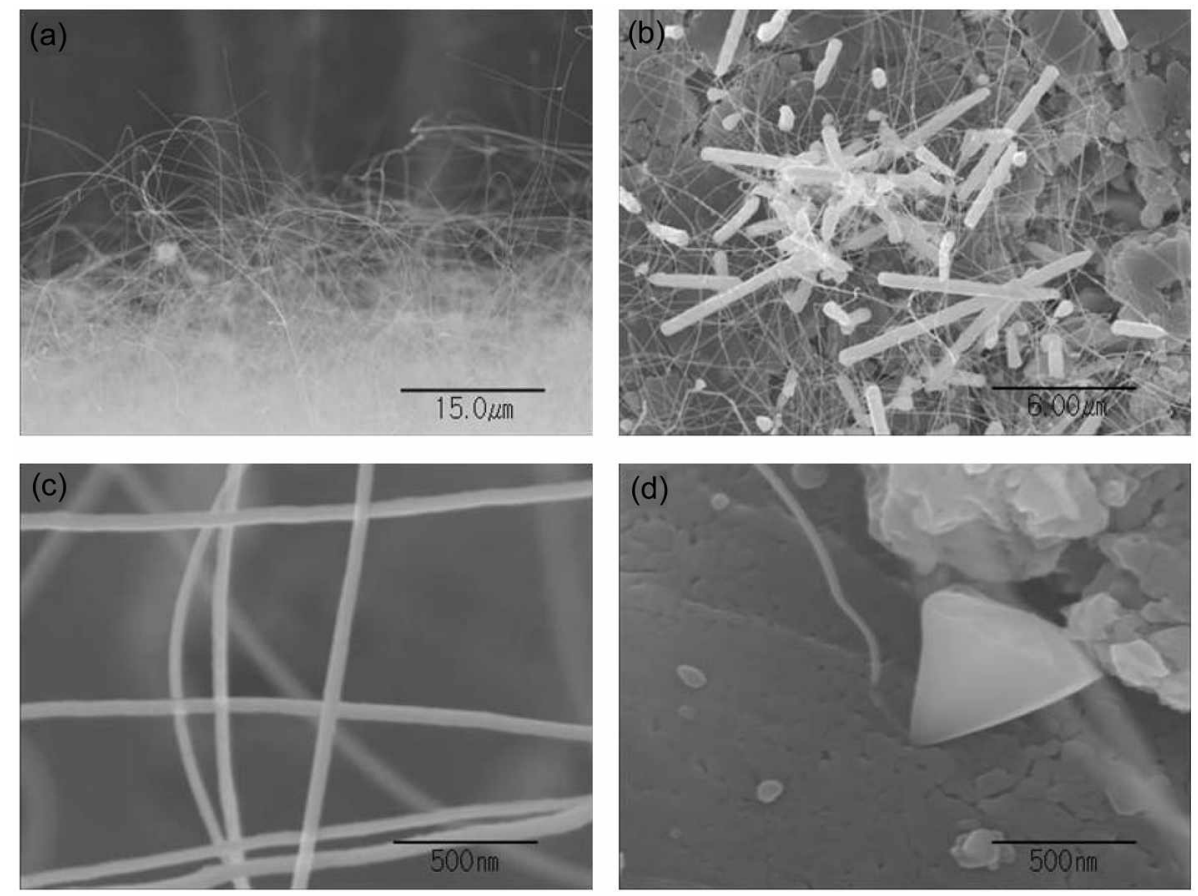

Figure 2. SEM inicrographs of nano- and microstruetured GaN obtained by calcining the pellet containing a mixture of GaOOH and $\mathrm{AlOOH}$ at $950^{\circ} \mathrm{C}$ for $5 \mathrm{~h}$ under a flow of ammonia.

${ }^{\circ} \mathrm{C}$ had a small amount of $\mathrm{GaN}$ nanorods or nanowires, showing the confinement effect. ${ }^{10.11}$ That is to say, GaN vapor is confined and easily supersaturated in a very small space. It is noted that no GaN nanowires were obtained by nitridation of $\mathrm{GaOOH}$ powder under the same reaction condition. ${ }^{10}$

The pressurized pellet of the precursor powder was more favorable for formation of $\mathrm{GaN}$ nano- and microstructures than the precursor powder. Both nanowires and microstructures such as microcones, stacked microcones, and hexagonal prismatic microcrystals were found on the surface of the pellets which were nitrided between 700 and $950^{\circ} \mathrm{C}$. The relative yiejd of microstructures to nanowires and their total yield increased with the reaction temperature. At $700^{\circ} \mathrm{C}$ very few nanowires were obtained, while both at temperatures above $750^{\circ} \mathrm{C}$ nanowires and microstructures were obtained. Figure 2(a)-2(d) show GaN morphology of the sample obtained at $950^{\circ} \mathrm{C}$ for $5 \mathrm{~h}$. Figure 2(a) shows lots of very long nanowires at the edge of the pellet. As shown in Figure 2(b), there were many nanowires and corrugated hexagonal prismatic microcrystals with one end being tapered. The nanowires were relatively homogeneous in diameter, which is as thick as $50 \mathrm{~nm}$ (Figure 2(c)). Figure 2(d) shows that the nanowires and microcones grew up out of the inner side of the pellet.

The confinement of $\mathrm{GaN}$ vapor in voids derived by pressurization of the precursor powder might be responsible for the growth of GaN nanowires and microstructures. The voids act as a confined reactor like carbon nanotube ${ }^{\gamma}$ and anodic alumina membrane. We propose that nano- and microstructured GaN might grow by the vapor-solid (VS) mechanism. According to the VS mechanism, GaN vapor is supersaturated in a confined reactor made of alumina, condensed, and then nucleated at the alumina wall. Continuous diffusion of $\mathrm{GaN}$ vapor into the reactor makes one-dimensional $\mathrm{GaN}$ nano- and microstructures grow out of the inner side of the pellet. On the basis of the following experimental results we rule out the possibility of the vaporliquid-solid (VLS) mechanism in which the Ga droplet derived from decomposition of $\mathrm{GaN}$ plays a role of catalyst. $\mathrm{Ga}$ droplets, if they are formed during the reaction, will be supersaturated with GaN vapor and the nanostructures will grow. First, no GaN nanostructures were found using the pure $\mathrm{GaOOH}$ powder as a precursor. ${ }^{10}$ If the VLS mechanism operates, the nanostructures should be found in the reaction system. Second, $\mathrm{GaOOH}$ powder in a $\mathrm{NaF}$ matrix transformed into $\mathrm{GaN}$ powder at $900{ }^{\circ} \mathrm{C}$ under a flow of $\mathrm{NH}_{3}$, but no $\mathrm{GaN}$ nanostructures were observed. If the VLS mechanism operates in a confined reactor, GaN nanostructures will grow in the reactor irrespective of its material. Therefore, this leads to the conclusion that the GaN nano- and microstructures grew out of the inner of an alumina matrix by the VS mechanism.

We observed the growth of GaN nano- and microstrucures on the c-plane of sapphire which was placed on the pellet. The GaN structures are also thought to grow via the VS mechanism because there was no Ga droplet on the sapphire. Stach $e t$ al. observed the growth of GaN nanowires on the sapphire via the self-catalytic VLS mechanism, in which the catalyst is nanoscale Ga liquid droplets evolved by thermal decomposition of GaN. ${ }^{12}$ However, they did not exclude the possibility of GaN nanowire growth via the VS mechanism.

As shown in Figure 3, we also obtained GaN microstructures such as hexagonal microcones, stacked microcones, 

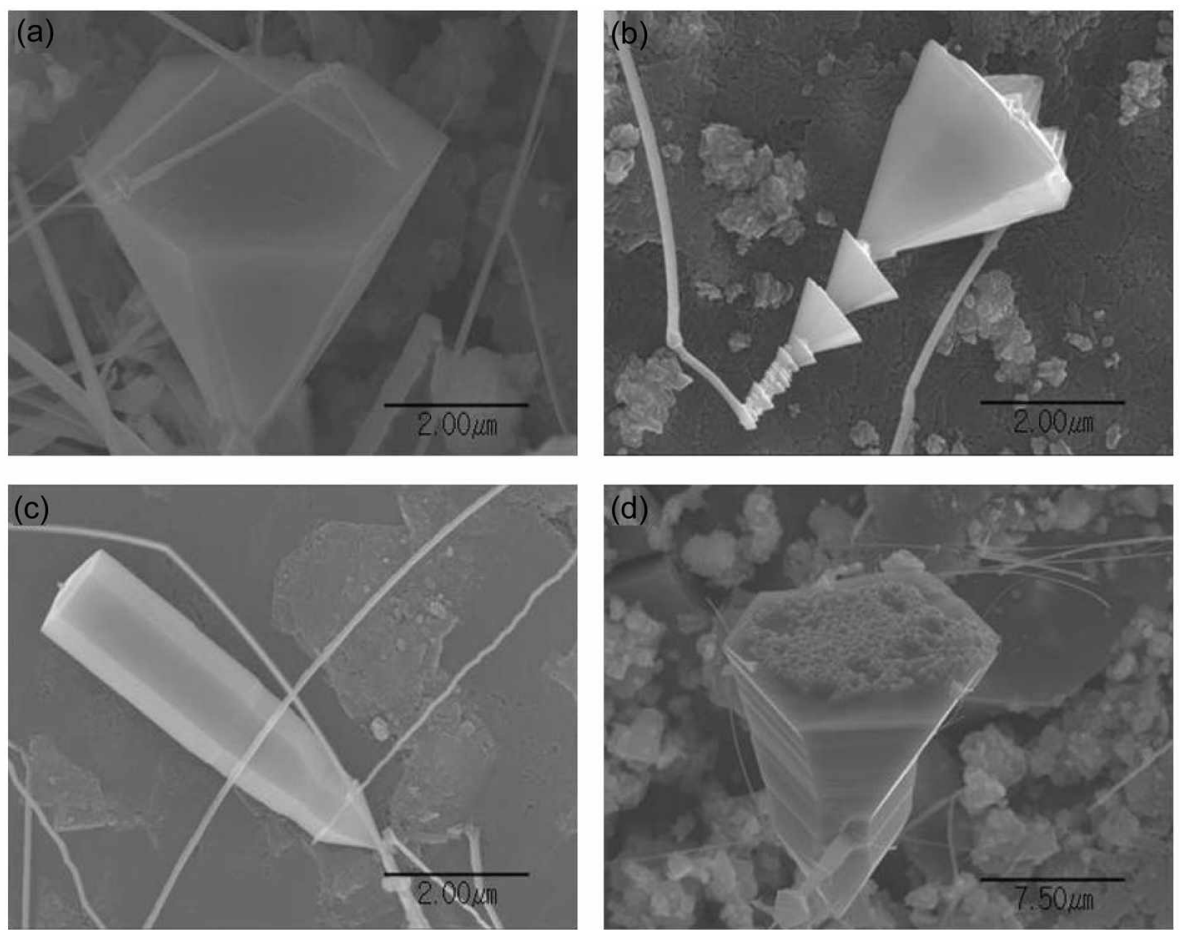

Figure 3. Various morphology of microstructured $\mathrm{GaN}$ obtained by calcining the pellet containing a mixture of $\mathrm{GaOOH}$ and $\mathrm{AlOOH}$ under a flow of amınonia: (a) hexagonal microcone, (b) stacked microcone, (c) hexagonal prismatic microcrystal, and (d) inmature hexagonal prisinatic inicrocrystal.

and hexagonal prisms, which were not prepared using other confined reactors. ${ }^{8.9}$ The yield of microstructures increased with the reaction temperature. It is inferred from Figure 3 that the hexagonal microcone grows to either the stacked microcone or hexagonal prismatic microcystal and the latter microstructure grows via the structure as shown in Figure 3(d). To our knowledge, such microstructures produced by the nitridation of $\mathrm{Ga}_{2} \mathrm{O}_{3}$ have not been reported in the literature. Stacked-cones have been grown by the CVD method recently. ${ }^{2+13}$ Cai et al. prepared a mixture of stacked-cone and smooth-surface $\mathrm{GaN}$ nanowires on Nicoated Si substrates by evaporation of $\mathrm{Ga}$ in $\mathrm{NH}_{3} / \mathrm{Ar}$ gas flow and found that the yield of the two types of nanowires depend on the $\mathrm{NH}_{3}$ flow rate. ${ }^{2}$ They suggested that the more $\mathrm{N}$-rich condition favors the stacked-cone morphology. ${ }^{2}$ But in this study the relative yield of $\mathrm{GaN}$ nanostructures did not depend on the $\mathrm{NH}_{3}$ flow rate but depended on the reaction temperature. It seems, therefore, that the diffusion rate of $\mathrm{GaN}$ vapor into the confined reactor has an effect on the morphology. It is well known that the degree of supersaturation detemines the prevailing growth morphology. A low supersaturation is required for one-dimensional nanostructure (such as whisker, nanorod and nanowire) growth, whereas a medium supersaturation support bulk crystal growth. $^{14}$ The low diffusion rate at relatively low reaction temperatures causes a low degree of supersaturation in the confined reactor that favors the formation of smooth nanowires, while the high diffusion rate at higher reaction temperatures causes a medium degree of supersaturation that favors the formation of microstructures. The stacked microcones may be attributed to the oscillation of supersaturation because of discontinous diffusion rate of $\mathrm{GaN}$ vapor. ${ }^{2}$

Han et $a l^{8}$ and Cheng $e t a l^{9}$ reported that only GaN nanowires were synthesized using nanometer confined reactors such as carbon nanotubes and anodic alumina membranes which were placed on a mixture of $\mathrm{Ga}$ and $\mathrm{Ga}_{2} \mathrm{O}_{3}$. They assumed that $\mathrm{Ga} 2 \mathrm{O}$ vapor would evolve by the reaction between $\mathrm{Ga}$ and $\mathrm{Ga}_{2} \mathrm{O}_{3}$. The reason why no other nanostructures than the nanowire were formed might be explained in terms of the degree of supersaturation in the confined reactor. It may be difficult for the $\mathrm{Ga}_{2} \mathrm{O}$ vapor to diffuse into the nanometer confined reactor and then react with $\mathrm{NH}_{3}$, and thereby for the reactor to be saturated with $\mathrm{GaN}$ vapor at a low degree of supersaturation. As mentioned, the low degree of supersaturation causes the formation of $\mathrm{GaN}$ nanowires. On the other hand, the confined reactor employed in this study is easily supersaturated with $\mathrm{GaN}$ vapor because it contains a $\mathrm{Ga}$ source whereby $\mathrm{GaN}$ vapor easily diffuses into the reactor, resulting in the low and medium degree of supersaturation. If the reaction temperature increases, a medium degree of supersaturation will be reached more easily.

To conclude, we synthesized two main types of $\mathrm{GaN}$ nanowires and microstructures by calcining a confined reactor made of alumina containing $\mathrm{Ga}_{2} \mathrm{O}_{3}$ at temperatures above $700^{\circ} \mathrm{C}$ under a flow of ammonia, and suggested that they grow by the VS mechanism in the reactor. It was found that the material of the reactor has an effect on their growth and the relative yield of the two types depends on the reaction temperature. 
Acknowledgements. This work was supported by Yeungnam University Research Grant (106117). SEM and XRD were recorded at the Yeungnam University Instrumental Analysis Center.

\section{References}

1. Stem. E.; Cheng, G.; Cimpoiasu. E.; Klie. R.; Guthrie, S.; Klemic. J.; Kretzschmar, I.; Steinlauf, E.; Turner-Evans, D.; Broomfreld, E.; Hyland, J.; Koudelka, R.; Boone, T.; Young, M.; Sanders, A.; Munden, R.; Lee, T.; Routenberg, D.; Reed, M. A. Nanotechnolog. $2005,16,2941$.

2. Cai, X. M.; Djuisic, A. B.; Xie, M. H.; Chiu, C. S.; Gwo, S. Appl. Phys. Lett. 2005. 87, 183103.

3. Ha, B.; Seo, S. H.; Cho, J. H.; Yoon, C. S.; Yoo, J.; Yi, G.-C.; Park, C. Y.; Lee, C. J. J. Phrs, Chem. B 2005, $109,11095$.

4. Bae, S. Y.; Seo, H. W.; Han, D. S.; Park, M. S.; Jang, W. S.; Na, C.
W.; Park, J.; Park, C. S. J. Crystal Growth 2003, 258, 296.

5. Chen, C.-C.; Yeh, C.-C.; Chen, C.-H.; Yu, M.-Y.; Liu, H.-L.; Wu, J.-J.; Chen, K.-H.; Chen, L.-C.; Peng, J.-Y.; Chen, Y.-F. J. Am. Chem. Soc. 2001, 123,2791 .

6. Chen, C.-C.; Yeh, C.-C. Adv. Mater, 2000, 12, 738.

7. Liu, B.; Bando, Y.; Tang, C.; Xu, F.; Golberg, D. Appl. Ph:s. Lett. 2005, 87, 073106.

8. Han, W.; Fan, S.; Li, Q.; Hu, Y. Science 1997, 277, 1287.

9. Cheng, G. S.; Zhang, L. D.; Zhu, Y.; Fei, G T.; Li, L.; Mo, C. M.; Mao, Y. Q. Appl. Phys. Lett. 1999, 75, 2455.

10. Jung, W.-S.; Min, B.-K. Mater, Lett. 2004, 58, 3058.

I1. Jung, W.-S. Bull. Korean Chem. Soc. 2004, 25, 5 I.

12. Stach, E. A.; Pauzauskie, P. J.; Kuykendall, T.; Goldberger, J.; He, R.; Yang. P. Nano Lett. 2003, 3, 867.

13. Peng. H. Y.; Wang, N.; Zhou, X. T.; Zheng. Y. F.; Lee, C. S.; Liao, L. S.; Lee, S. T. Chem. Phys. Lett, 2002, 359, 24l.

14. Campbell, W. B. In Whisker Techolog; Levitt, A. P., Ed.; WileyInterscience: New York, U. S. A., 1970; Chap. 2. 